\title{
Influence of high-density lipoprotein cholesterol on coronary collateral formation in a population with significant coronary artery disease
}

\author{
Po-Chao Hsu ${ }^{1,2}$, Ho-Ming Su, ${ }^{1,6,7}$, Suh-Hang Juo ${ }^{3,4,5}$, Hsueh-Wei Yen ${ }^{1,6}$, Wen-Chol Voon ${ }^{1,6}$, Wen-Ter Lai ${ }^{1,6}$,
} Sheng-Hsiung Sheu ${ }^{1,6}$ and Tsung-Hsien Lin ${ }^{1,6^{*}}$

\begin{abstract}
Background: Coronary collateral circulation plays an important role in protecting myocardium from ischemia and reducing cardiovascular events. Low High-density lipoprotein cholesterol (HDL-C) level is a strong risk factor for coronary artery disease (CAD) and is associated with poor cardiovascular outcome. It was recently reported to be associated with poor coronary collateral development in Turkish population. Hence, we investigated the influence of HDL-C on coronary collateral formation in Chinese population.

Methods: We evaluated 970 consecutive patients undergoing coronary angiography, and 501 patients with significant coronary artery disease (SCAD) were finally analyzed. The collateral scoring system developed by Rentrop was used to classify patient groups as those with poor or good collaterals.

Results: The patients with poor collaterals had fewer diseased vessels $(1.97 \pm 0.84$ vs $2.47 \pm 0.68, p<0.001)$ and lower diffuse score $(2.65 \pm 1.63$ vs $3.76 \pm 1.78, \mathrm{p}<0.001)$. There was no significant difference in HDL-C and other variables between good and poor collaterals. Multivariate analysis showed only number of diseased vessels (odd ratio $0.411, p<0.001$ ) was a significant predictor of poor collateral development.
\end{abstract}

Conclusions: The extent of CAD severity but not HDL-C level was the most powerful predictor of coronary collateral formation in our Chinese population with SCAD.

Keywords: Coronary artery disease, Coronary collateral circulation, High-density lipoprotein cholesterol

\section{Background}

Cardiovascular disease is one of the leading causes of morbidity and mortality in the world. Low high-density lipoprotein cholesterol (HDL-C) is an independent risk factor for coronary artery disease (CAD) and is associated with increased cardiovascular event [1-3].

The development of coronary collaterals is an adaptive response to chronic myoischemia and serves as a conduit bridging the significantly stenotic coronary vessels [4-6]. Collateral circulation can hence protect and preserve myocardium from episodes of ischemia, enhance residual myocardial contractility, and reduce angina

\footnotetext{
* Correspondence: Ith@kmu.edu.tw

'Department of Internal Medicine, Division of Cardiology, Kaohsiung Medical University, 100 Tzyou 1st Road, Kaohsiung 80708, Taiwan, ROC

${ }^{6}$ Department of Internal Medicine, Faculty of Medicine, Kaohsiung, Taiwan

Full list of author information is available at the end of the article
}

symptoms and cardiovascular events [7-9]. However, there is inter-individual difference of coronary collateral formation and the mechanisms for different individual ability to develop collateral circulation are still not well understood.

Furthermore, HDL-C was also recently reported to be associated with poor coronary collateral development in a Turkish population [10]. Hence, we wanted to investigate the influence of HDL-C on coronary collateral formation in a Chinese population with significant CAD (SCAD).

\section{Methods}

\section{Study subjects}

From February 2002 to March 2008, we evaluated 970 consecutive patients who had been scheduled to undergo diagnostic coronary angiography at Kaohsiung

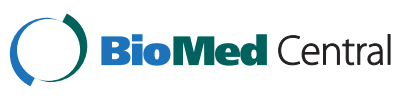


Medical University Hospital in Taiwan. We excluded patients with coronary artery lumen diameter stenosis $<70 \%$, history of coronary artery bypass surgery (CABG), history of percutaneous coronary intervention (PCI), or those who had inadequate angiograms for collateral evaluation. Finally, 501 patients with significant CAD were enrolled in this study. Other analyzed demographic and baseline data included gender, age, and any history of the following: diabetes mellitus, hypertension, hypercholesterolemia, body mass index, cigarette smoking, and medications. The research protocol was approved and registered by the ethics committee (Kaohsiung Medical University Hospital- Institutional Review Board) at our institution, and informed consent was obtained from all patients.

\section{Coronary angiography and collateral scoring}

The coronary artery angiography films were reviewed by 2 experienced cardiologists blinded to the clinical and demographic data for all patients. Any differences in interpretation were resolved by a third reviewer who was blinded to the readings of the first two reviewers. Coronary artery stenosis was determined by quantitative coronary angiography. The recorded data also included the number of diseased vessels, the vessel to which the collaterals were connected, and the grade of coronary collateral circulation. Vessels exhibiting a $70 \%$ or greater reduction in lumen diameter were classified as SCAD. In subjects with more than one SCAD vessel, the vessel with the highest collateral grade was chosen for analysis. The collateral scoring system developed by Rentrop and Cohen was used [11]. Grades of collateral filling from the contralateral vessel were: $0=$ none; $1=$ filling of side branches of the artery to be dilated via collateral channels without visualization of the epicardial segment; 2 = partial filling of the epicardial segment via collateral channels; 3 =complete filling of the epicardial segment of the artery being dilated via collateral channels. In subjects with more than one collateral vessel supplying the distal aspect of the diseased artery, the highest collateral grade was recorded. Patients were then classified according to their collateral grades as either poor (grade 0 or grade 1 collateral circulation) or good (grade 2 or grade 3 collateral circulation). The coronary artery angiography films were reviewed by two experienced cardiologists blinded to the clinical and demographic data for all patients. Any differences in interpretation were resolved by a third reviewer who was blinded to the readings of the first two reviewers. The two readers obtained a $96 \%$ agreement in the collateral classifications.

\section{CAD severity scoring by coronary angiography}

We evaluated the extent of coronary artery atherosclerosis by a "diffuse score" (DS) developed by Negri et al. and modified by Birnie et al. [12,13]. In brief, the coronary circulation is divided into 15 segments, and eight of them are classified as first-order segments: proximal and middle right coronary arteries, left main coronary artery, proximal, middle, and distal left anterior descending, and proximal and distal circumflex. There are seven second-order segments: distal right coronary artery, posterior descending branch, obtuse marginal branch, postero-lateral branch of circumflex, and the first two diagonal branches of the left anterior descending artery. The first-order segments receive a score of 1 and the second order segments scored 0.5. The overall DS is the sum of the individual segment scores and the maximum score is 11.5 .

\section{Statistical analysis}

All data were expressed as means \pm standard deviation. Student unpaired $t$-test was used to compare continuous variables between the two groups. Chi-square test was used to compare categorical data. Subsequently, age, sex, significantly correlated variables in the univariate analysis or relevant variables were further analyzed by logistic regression analysis. All $\mathrm{p}$ values were two-sided with a significance level of $\mathrm{p}<.05$. The Statistical Package for the Social Sciences 11.0 for Windows (SPSS Inc., Chicago, IL) was used for statistical analysis.

\section{Results}

\section{Clinical characteristics}

Of the 970 subjects initially enrolled, 469 patients were excluded for the following reasons: coronary artery lumen diameter stenosis $<70 \%$, history of CABG or PCI, or inadequate angiograms for collateral evaluation. The final study population was 501 subjects (396 male, 105 female; average age, $62.5 \pm 12.6$ years). For SCAD, 134 patients $(26.7 \%)$ were one-vessel disease, 153 patients $(30.5 \%)$ were two-vessel disease, and 214 patients $(42.7 \%)$ were three-vessel disease.

\section{Coronary collaterals}

The two readers obtained a 96\% agreement in the collateral classifications. Of the 501 patients enrolled, 220 (43.9\%) patients had no coronary collaterals. In subjects with collaterals, the coronary grade was distributed as follows: $91(18.2 \%)$ with grade 1, 133 (26.5\%) with grade 2 and $57(11.4 \%)$ with grade 3 . Table 1 compares the baseline characteristics between the poor group $(n=$ 311 ) and the good group ( $n=190)$. The patients in the poor group had a trend to have lower cholesterol level $(199.7 \pm 45.1$ vs $208.3 \pm 53.6, p=0.06)$, lower low-density lipoprotein cholesterol (LDL-C) level (128.7 \pm 38.3 vs $136.2 \pm 43.5, \mathrm{p}=0.066)$, less angiotensin II receptor blocker (ARB) usage (15.9\% vs $22.3 \%, \mathrm{p}=0.09)$, and less beta blocker usage ( $28 \%$ vs $36.7 \%, \mathrm{p}=0.054$ ). 
Table 1 Baseline characteristics in patients with poor and good collaterals

\begin{tabular}{|c|c|c|c|}
\hline Variables & $\begin{array}{l}\text { Poor collateral } \\
\qquad(n=311)\end{array}$ & $\begin{array}{l}\text { Good collateral } \\
\qquad(n=190)\end{array}$ & $\begin{array}{c}P \\
\text { value }\end{array}$ \\
\hline Age (years) & $62.8 \pm 12.9$ & $62.1 \pm 12.1$ & 0.547 \\
\hline Gender (Female, \%) & 22.5 & 18.4 & 0.309 \\
\hline DM (\%) & 42.8 & 40.5 & 0.642 \\
\hline HTN (\%) & 64.3 & 65.3 & 0.848 \\
\hline Smoking (\%) & 60.5 & 58.2 & 0.639 \\
\hline BMI & $24.3 \pm 6.6$ & $24.9 \pm 5.7$ & 0.277 \\
\hline eGFR (mL/min/1.73 m2) & $66.9 \pm 26.9$ & $68.0 \pm 32.0$ & 0.683 \\
\hline \multicolumn{4}{|l|}{ Laboratory data } \\
\hline Glucose (mg/dl) & $137.7 \pm 62.2$ & $135.4 \pm 60.4$ & 0.704 \\
\hline Cholesterol (mg/dl) & $199.7 \pm 45.1$ & $208.3 \pm 53.6$ & 0.060 \\
\hline LDL-C (mg/dl) & $128.7 \pm 38.3$ & $136.2 \pm 43.5$ & 0.066 \\
\hline $\mathrm{HDL}-\mathrm{C}(\mathrm{mg} / \mathrm{dl})$ & $37.4 \pm 9.9$ & $36.0 \pm 10.6$ & 0.175 \\
\hline Triglyceride (mg/dl) & $168.9 \pm 124.9$ & $163.4 \pm 146.4$ & 0.660 \\
\hline Uric acid (mg/dl) & $6.54 \pm 1.94$ & $6.58 \pm 1.81$ & 0.819 \\
\hline \multicolumn{4}{|l|}{ Medication } \\
\hline ACEI (\%) & 19.1 & 20.7 & 0.725 \\
\hline ARB (\%) & 15.9 & 22.3 & 0.09 \\
\hline Beta blocker (\%) & 28 & 36.7 & 0.054 \\
\hline
\end{tabular}

Angiographic characteristics in patients with poor and good collaterals are shown in Table 2; the patients with poor collaterals had fewer diseased vessels numbers $(1.97 \pm 0.84$ vs $2.47 \pm 0.68, \mathrm{p}<0.001)$, and lower severity scores of CAD $(2.65 \pm 1.63$ vs $3.76 \pm 1.78, \mathrm{p}<0.001)$.

\section{Binary logistic regression analysis}

Age, sex, significant variable in the univariate analysis and relevant variables including cholesterol level, LDL-C level, HDL-C level, ARB usage, and beta blocker usage were included in the multivariate logistic regression analysis. We found the number of diseased vessels $(\mathrm{OR}=$

Table 2 Angiographic characteristics in patients with poor and good collaterals

\begin{tabular}{lccc}
\hline Mean \pm SD & $\begin{array}{c}\text { Poor collateral } \\
(\mathbf{n = 3 1 1 )}\end{array}$ & $\begin{array}{c}\text { Good collateral } \\
\mathbf{( n = 1 9 0 )}\end{array}$ & $\begin{array}{c}\mathbf{P} \\
\text { value }\end{array}$ \\
\hline Number (\%) & $1.97 \pm 0.84$ & $2.47 \pm 0.68$ & $<0.001$ \\
Significant CAD, n (\%) & & & \\
1 vessel disease (\%) & $114(36.7)$ & $20(10.5)$ & \\
2 vessel disease (\%) & $93(29.9)$ & $60(31.6)$ & $<0.001$ \\
3 vessel disease (\%) & $104(33.4)$ & $110(57.9)$ & \\
Diffuse score of CAD & $2.65 \pm 1.63$ & $3.76 \pm 1.78$ & $<0.001$ \\
\hline
\end{tabular}

CAD: coronary artery disease.
$0.410,95 \% \mathrm{CI}=0.31-0.55, \mathrm{p}<0.001)$ was the only significantly independent predictor of poor coronary collaterals development (Table 3).

\section{Discussion}

In the current study, we investigated the influence of HDL-C on coronary collateral formation in Chinese population with SCAD and found two major findings. First, HDL-C was not significantly associated with coronary collateral formation in a Chinese population as a previous study in a Turkish population. Second, the number of diseased vessels was the only significantly independent predictor of poor coronary collaterals in the Chinese population. This finding was also different from previous studies in a Turkish population.

\section{The association between HDL-C level and coronary collaterals}

HDL-C has been reported to have anti-atherogenic, antiinflammatory, and antioxidant properties in the literature [14-16]. Although Sumi M et al. also showed that reconstituted HDL-C directly stimulates endothelial progenitor cell differentiation via phosphatidylinositol 3kinase/Akt pathway and enhances ischemia-induced angiogenesis, we did not find HDL-C was associated with coronary collateral development in this population study [17]. In addition, Low HDL-C level was a strong risk factor for coronary artery disease and was associated with poor cardiovascular outcome [1-3]. In a previous study, Turhan $\mathrm{H}$ et al. reported that the development of coronary collateral vessels is poorer in patients with metabolic syndrome with advanced ischemic heart disease than in control participants without metabolic syndrome in a Turkish population, which suggested that metabolic syndrome is one of the significant factors affecting the development of coronary collateral vessels adversely [18]. Although low HDL-C is one of the

Table 3 Multivariate logistic regression analysis of collateral circulation (good collateral group as reference group)

\begin{tabular}{lcccc}
\hline & B & OR & $\mathbf{9 5 \% ~ C l}$ & p value \\
\hline Gender (male vs female) & -0.268 & 0.765 & $0.42-1.41$ & 0.390 \\
Age & 0.010 & 1.010 & $0.99-1.03$ & 0.326 \\
Cholesterol $(\mathrm{mg} / \mathrm{dl})$ & 0.003 & 1.003 & $0.99-1.01$ & 0.440 \\
LDL-C $(\mathrm{mg} / \mathrm{dl})$ & -0.007 & 0.993 & $0.98-1.00$ & 0.135 \\
HDL-C $(\mathrm{mg} / \mathrm{dl})$ & 0.018 & 1.018 & $0.99-1.04$ & 0.160 \\
ARB usage & -0.422 & 0.656 & $0.37-1.17$ & 0.155 \\
Beta blocker usage & -0.380 & 0.684 & $0.42-1.11$ & 0.126 \\
Number of diseased vessels & -0.892 & 0.410 & $0.31-0.55$ & $<0.001$ \\
\hline ARB: angiotensin
\end{tabular}

ARB: angiotensin II receptor blocker; HDL-C: high-density lipoprotein cholesterol; LDL-C: low-density lipoprotein cholesterol. 
diagnostic criteria for metabolic syndrome, they did not report and we also did not find HDL-C was associated with coronary collateral formation. Recently, Kadi $\mathrm{H}$ et al. further investigated the relationship between HDL-C and coronary collateral formation in patients with SCAD and found that there was a positive relationship between HDL-C and coronary collateral formation and suggested that low HDL-C is an independent predictor of poor coronary collateral formation in a Turkish population [10]. However, Li CC et al. reported that severity of coronary stenosis was the major influencing factor in coronary collateral formation and function in a Chinese population. Serum HDL-C was not associated with coronary collateral formation, but related to coronary collateral function which was evaluated by the size of the collateral connection diameter [19]. In our study, we analyzed 501 Chinese patients with SCAD to evaluate the correlation between HDL-C and coronary collaterals. Our result showed there was no significant association between HDL-C and coronary collateral formation not only in univariate but also in multivariate analysis, which was different from a previous study in a Turkish population. The advantages of our study were that we had a larger sample size and selected more severe coronary artery lesions than the previous study [10]. In their study, the sample size was relatively small and vessels with 50-70\% stenosis were selected for coronary collateral evaluation, which may not cause severe myoischemia to induce coronary collateral formation [6]. In addition, the influence of HDL-C for coronary collateral development might not be similar between different races because of genetic diversity. However, the detailed mechanism still needs further investigation.

\section{The association between CAD severity and coronary collaterals}

It is well known that coronary collateral formation is mainly dependent on CAD severity [20-22]. Coronary collateral formation is an adaptive response to chronic myoischemia and serves as a conduit bridging significantly stenotic coronary vessels. More severe and extensive myocardial ischemia such as multi-vessel diseases may further stimulate the development of coronary collateral circulation. Hence, patients with good coronary collaterals appear to have a more extensive CAD. In previous studies, number of diseased vessels was a significant predictor of good collateral formation [20,23]. In our study, number of diseased vessels was not only associated with good collateral formation in univariate analysis but in multivariate analysis as well. In addition, we also used DS to further evaluate the extent of CAD severity and found that there was also a significant difference of DS between patients with poor and good coronary collaterals. Hence, extent of coronary atherosclerosis significantly plays an important role in coronary collateral formation $[24,25]$.

\section{Limitations of the present study}

First, the collateral formation was assessed by coronary angiography in this study. Measuring collateral flow index by intravascular Doppler guidewire may provide a more objective physiological measurement of collateral grade. However, the invasiveness of intravascular ultrasound limits its use in large-scale studies. Second, since this was only a clinical observational study, potential mechanisms were not fully elucidated. Third, we did not analyze the size of the collateral connection diameter to evaluate the coronary collateral function.

\section{Conclusions}

In conclusion, our data revealed that HDL-C was not associated with coronary collateral formation in a Chinese population with SCAD; however, CAD severity implicated by number of diseased vessels was the only significant predictor of coronary collateral development in our study.

\section{Competing interests}

The authors have no competing interests to declare.

\section{Authors' contributions}

PCH: study concept and design, analysis and interpretation of data and drafting the manuscript. HMS, SHJ, SHS, and WTL: study concept and design, acquisition of subjects. HWY, WCV: Providing intellectual content of critical importance to the work described. THL: study concept and design, preparation of manuscript, and final approval of the version. All authors read and approved the final manuscript.

\section{Author details}

${ }^{1}$ Department of Internal Medicine, Division of Cardiology, Kaohsiung Medical University, 100 Tzyou 1st Road, Kaohsiung 80708, Taiwan, ROC. ${ }^{2}$ Graduate Institute of Medicine, Kaohsiung Medical University, Kaohsiung, Taiwan. ${ }^{3}$ Department of Medical Research, Kaohsiung Medical University Hospital, Kaohsiung, Taiwan. ${ }^{4}$ Medical Genetics, Kaohsiung, Taiwan. ${ }^{5}$ Center of Excellence for Environmental Medicine, Kaohsiung Medical University, Kaohsiung, Taiwan. 'Department of Internal Medicine, Faculty of Medicine, Kaohsiung, Taiwan. ${ }^{7}$ Department of Internal Medicine, Kaohsiung Municipal Hsiao-Kang Hospital, Kaohsiung, Taiwan.

Received: 24 October 2012 Accepted: 13 March 2013

Published: 20 March 2013

\section{References}

1. Gordon DJ, Rifkind BM: High-density lipoprotein - the clinical implications of recent studies. N Engl J Med 1989, 321:1311-1316.

2. Rubins HB, Schectman G, Wilt TJ, Iwane MK: Distribution of lipid phenotypes in community-living men with coronary heart disease. High prevalence of isolated low levels of high-density lipoprotein cholesterol. Arch Intern Med 1992, 152:2412-2416.

3. Abbott RD, Wilson PW, Kannel WB, Castelli WP: High-density lipoprote in cholesterol, total cholesterol screening, and myocardial infarction. The Framingham Study. Arteriosclerosis 1998, 8:207-211.

4. Fujita M, Sasayama S, Ohno A, Nakajima H, Asanoi H: Importance of angina for development of collateral circulation. Br Heart J 1987, 57:139.

5. Tayebjee MH, Lip GY, MacFadyen RJ: Collateralization and the response to obstruction of epicardial coronary arteries. QJM 2004, 97:259.

6. Levin DC: Pathways and functional significance of the coronary collateral circulation. Circulation 1974, 50:831.

7. Cohen M, Rentrop KP: Limitation of myocardial ischemia by collateral circulation during sudden controlled coronary artery occlusion in human subjects: a prospective study. Circulation 1986, 74(3):469-476. 
8. Meier $\mathrm{P}$, Gloekler $\mathrm{S}$, Zbinden $\mathrm{R}$, Beckh $\mathrm{S}$, de Marchi SF, Zbinden $\mathrm{S}$, Wustmann K, Billinger M, Vogel R, Cook S, Wenaweser P, Togni M, Windecker S, Meier B, Seiler C: Beneficial effect of recruitable collaterals: a 10-year follow-up study in patients with stable coronary artery disease undergoing quantitative collateral measurements. Circulation 2007, 116(9):975-983.

9. Regieli JJ, Jukema JW, Nathoe HM, Zwinderman AH, Ng S, Grobbee DE, van der Graaf Y, Doevendans PA: Coronary collaterals improve prognosis in patients with ischemic heart disease. Int J Cardiol 2009, 132(2):257-262

10. Kadi H, Ozyurt H, Ceyhan K, Koc F, Celik A, Burucu T: The relationship between high-density lipoprotein cholesterol and coronary collateral circulation in patients with coronary artery disease. J Investig Med 2012, 60(5):808-12.

11. Rentrop KP, Cohen M, Blanke H, Phillips RA: Changes in collateral channel filling immediately after controlled coronary artery occlusion by an angioplasty balloon in human subjects. J Am Coll Cardiol 1985, 5(3):587-592.

12. Negri M, Sheiban I, Arigliano PL, Tonni S, Montresor G, Carlini S, Manzato F: Interrelation between angiographic severity of coronary artery disease and plasma levels of insulin, C-peptide and plasminogen activator inhibitor-1. Am J Cardiol 1993, 72:397-401.

13. Birnie DH, Holme ER, McKay IC, Hood S, McColl KE, Hillis WS: Association between antibodies to heat shock protein 65 and coronary atherosclerosis. Possible mechanism of action of Helicobacter pylori and other bacterial infections in increasing cardiovascular risk. Eur Heart $J$ 1998, 19:387-94.

14. Oram JF, Vaughan AM: ATP-binding cassette cholesterol transporters and cardiovascular disease. Circ Res 2006, 99:1031-1043.

15. Cockerill GW, Rye KA, Gamble JR, Vadas MA, Barter PJ: High-density lipoproteins inhibit cytokine-induced expression of endothelial cell adhesion molecules. Arterioscler Thromb Vasc Biol 1995, 15:1987-1994.

16. Suc I, Escargueil-Blanc I, Troly M, Salvayre R, Nègre-Salvayre A: HDL and ApoA prevent cell death of endothelial cells induced by oxidized LDL. Arterioscler Thromb Vasc Biol 1997, 17:2158-2166.

17. Sumi M, Sata M, Miura S, Rye KA, Toya N, Kanaoka Y, Yanaga K, Ohki T, Saku K, Nagai R: Reconstituted high-density lipoprotein stimulates differentiation of endothelial progenitor cells and enhances ischemiainduced angiogenesis. Arterioscler Thromb Vasc Biol 2007, 27(4):813-8.

18. Turhan H, Yasar AS, Erbay AR, Yetkin E, Sasmaz H, Sabah I: Impaired coronary collateral vessel development in patients with metabolic syndrome. Coron Artery Dis 2005, 16(5):281-5.

19. Li CC, Yang TL, Pu XQ, Zheng ZF, Yu ZX, Chen XB, Chen F, Mo L, Hu DJ, Xie $\mathrm{QY}, \mathrm{He} \mathrm{L}$, Deng JH, Meng SY: Formation and function of coronary collateral circulation and their influencing factors. Zhong Nan Da Xue Xue Bao Yi Xue Ban 2004, 29(6):693-6.

20. Abaci A, Oğuzhan A, Kahraman S, Eryol NK, Unal S, Arinç H, Ergin A: Effect of diabetes mellitus on formation of coronary collateral vessels. Circulation 1999, 99(17):2239-2242.

21. Fulton WFM: The dynamic factor in enlargement of coronary arterial anastomoses, and paradoxical changes in the subendocardial plexus. Br Heart J 1964, 26:39-50.

22. Helfant RH, Kemp HG, Gorlin R: Coronary atherosclerosis, coronary collaterals, and their relation to cardiac function. Ann Intern Med 1970, 73:189-193.

23. Sezer M, Ozcan M, Okcular I, Elitok A, Umman S, Umman B, Tayyareci Y, Olcay A, Nisanci Y, Bilge AK, Meric M: A potential evidence to explain the reason behind the devastating prognosis of coronary artery disease in uraemic patients: renal insufficiency is associated with poor coronary collateral vessel development. Int J Cardiol 2007, 115(3):366-372.

24. Hsu PC, Lin TH, Su HM, Juo SH, Lai WT, Sheu SH: Association between endostatin G4349A polymorphism and coronary collaterals in the Chinese population. Acta cardiol Sin 2012, 28:10-16.

25. Hsu PC, Juo SH, Su HM, Chen SC, Tsai WC, Lai WT, Sheu SH, Lin TH: Predictor of poor coronary collaterals in chronic kidney disease population with significant coronary artery disease. BMC Nephrol 2012 13(1):98.

doi:10.1186/1756-0500-6-105

Cite this article as: Hsu et al:. Influence of high-density lipoprotein cholesterol on coronary collateral formation in a population with significant coronary artery disease. BMC Research Notes 2013 6:105.

\section{Submit your next manuscript to BioMed Central and take full advantage of:}

- Convenient online submission

- Thorough peer review

- No space constraints or color figure charges

- Immediate publication on acceptance

- Inclusion in PubMed, CAS, Scopus and Google Scholar

- Research which is freely available for redistribution 